\title{
Effect of Recombinant Prophenin 2 on the Integrity and Viability of Trichomonas vaginalis
}

\author{
J. L. Hernandez-Flores, ${ }^{1}$ M. C. Rodriguez, ${ }^{2}$ A. Gastelum Arellanez, ${ }^{3}$ \\ A. Alvarez-Morales, ${ }^{1}$ and E. E. Avila ${ }^{2}$ \\ ${ }^{1}$ Unidad Irapuato, Departamento de Ingeniería Genética, Centro de Investigación y de Estudios Avanzados del IPN, \\ P.O. Box 629, 36500 Irapuato, GTO, Mexico \\ ${ }^{2}$ Division de Ciencias Naturales y Exactas, Departamento de Biologia, Universidad de Guanajuato, Col. Noria Alta, \\ 36040 Guanajuato, GTO, Mexico \\ ${ }^{3}$ Universidad Politécnica del Mar y la Sierra, Carretera a La Cruz km 15.5, Col. Arroyitos, La Cruz, 82700 Elota, SIN, Mexico
}

Correspondence should be addressed to E. E. Avila; edilia@ugto.mx

Received 31 July 2014; Accepted 26 September 2014

Academic Editor: J. Eleazar Barboza-Corona

Copyright (C) 2015 J. L. Hernandez-Flores et al. This is an open access article distributed under the Creative Commons Attribution License, which permits unrestricted use, distribution, and reproduction in any medium, provided the original work is properly cited.

\begin{abstract}
Trichomonas vaginalis is the causal agent of trichomoniasis, which is associated with preterm child delivery, low birth weight, and an increased risk of infection by human papilloma virus and human immunodeficiency virus following exposure. Several reports have established increasing numbers of trichomoniasis cases resistant to metronidazole, the agent used for treatment, and it is therefore important to identify new therapeutic alternatives. Previously, our group reported the effect of tritrpticin, a synthetic peptide derived from porcine prophenin, on T. vaginalis; however, the hemolytic activity of this small peptide complicates its possible use as a therapeutic agent. In this study, we report that the propeptide and the processed peptide of prophenin 2 (cleaved with hydroxylamine) affected the integrity and growth of T. vaginalis and that pro-prophenin 2 displays some resistance to proteolysis by $T$. vaginalis proteinases at $1 \mathrm{~h}$. Its effect on $T$. vaginalis as well as its low hemolytic activity and short-time stability to parasite proteinases makes prophenin 2 an interesting candidate for synergistic or alternative treatment against T. vaginalis.
\end{abstract}

\section{Introduction}

Antimicrobial peptides (AMPs) are natural antibiotics synthesized by all known organisms, from bacteria to vertebrates; they have antimicrobial and immunoregulatory functions. AMPs are active against several infectious agents, including viruses, bacteria, fungi, and parasites [1-3]. Most studies have examined the effects of AMPs on bacteria, and fewer reports exist regarding their effects on protozoa [3-8]. In mammals, defensins and cathelicidins are AMPs that are widely expressed in phagocytic immune cells that migrate to infection sites [9].

Pigs have the most diverse collection of cathelicidins of any mammalian species, among which are the prolinephenylalanine-rich prophenin-1 (PF-1), prophenin-2 (PF-2), proline-arginine-rich PR-39, and cysteine-rich protegrins 1 to 5 (PG-1 to PG-5), which have been purified from neutrophils [10].

The protozoan flagellate Trichomonas vaginalis is the causal agent of trichomoniasis, the most common nonviral sexually transmitted disease. Trichomoniasis is associated with membrane rupture in pregnant women and, therefore, preterm child delivery, low birth weight, and augmented risk of infection with human papilloma virus or human immunodeficiency virus type 1 [11-14] following exposure. Trichomoniasis is treated with metronidazole or tinidazole, but several reports describe increasing numbers of cases resistant to these compounds [15-19]. AMPs are potential alternatives for trichomoniasis treatment, but $T$. vaginalis trophozoites are rich in cysteine proteinases that might 
degrade the peptides; some of these enzymes are surface associated, excreted/secreted, and involved in parasite adherence and cytopathogenicity [20-22].

We reported an interesting trichomonacidal effect of tritrpticin, a small peptide derived from the porcine prophenin 2 [23], but the complete prophenin 2 peptide has not been tested for activity against $T$. vaginalis or other protozoan pathogens. In addition, prophenin 2 is interesting because it should theoretically be resistant to the attack by $T$. vaginalis proteinases due to its high proline content, which may prevent cleavage of the peptide bonds [10, 24]. In this study, we demonstrated that pro-prophenin 2 is partially resistant to proteolysis by $T$. vaginalis proteinases at $1 \mathrm{~h}$ and that the complete propeptide and the processed prophenin 2 peptide diminished the integrity and growth of T. vaginalis.

\section{Materials and Methods}

2.1. Strains and Plasmids. Plasmids were propagated and maintained using E. coli DH5 $\alpha$ and purified using a Plasmid Midi Kit 100 (Qiagen, Cat. 12145). For protein expression, E. coli BL21 STAR was used. Both strains were grown at $37^{\circ} \mathrm{C}$ in Luria-Bertani medium supplemented with $100 \mathrm{mg} / \mathrm{L}$ carbenicillin $(\mathrm{LB} / \mathrm{Cb})$ when necessary. The plasmid pQETriSystem (Qiagen, Cat. 33903) was used to express proprophenin 2 .

T. vaginalis strain RFC-1 (ATCC) was grown in $8 \mathrm{~mL}$ screw-cap tubes with $5 \mathrm{~mL}$ of TYI-S-33 medium, $\mathrm{pH} 7.0$ [25], supplemented with $6 \%$ bovine serum. T. vaginalis was cultured for $72 \mathrm{~h}$ at $36.5^{\circ} \mathrm{C}$ to maintain trophozoites and for $24 \mathrm{~h}$ before assays.

2.2. Prophenin 2 Propeptide Cloning and Expression. The nucleotide sequence of the open reading frame corresponding to porcine pro-prophenin 2 [26] was optimized for E. coli codon usage. The optimized open reading frame was fused to an 8-amino acid FLAG tag [27] (Figure 1) followed by Western blot analysis and purification of the recombinant protein by affinity chromatography. The optimized pro-prophenin 2::FLAG tag was synthesized (Epoch Biolabs), cloned into the SmaI-EcoRI sites of the pQE-TriSystem expression vector and transformed into $E$. coli $\mathrm{DH} 5 \alpha$. Putative recombinant clones were confirmed by restriction analysis and sequencing. Confirmed clones were propagated using E. coli $\mathrm{DH} 5 \alpha$, and plasmid DNA was isolated; one clone, pUG2, was selected. To express pro-prophenin 2, E. coli BL21 STAR was transformed with the pUG2 construct and grown in $\mathrm{LB} / \mathrm{Cb}$. Overnight cultures were used to inoculate fresh $\mathrm{LB} / \mathrm{Cb}$ medium supplemented with $0.4 \%$ glucose and incubated at $37^{\circ} \mathrm{C}$ until the OD600 reached 0.5. IPTG was then added to a final concentration of $0.25 \mathrm{mM}$, and the cells were further incubated for $4 \mathrm{~h}$ at $37^{\circ} \mathrm{C}$. Cultures were centrifuged at $5,000 \times \mathrm{g}$ for 20 minutes at $4^{\circ} \mathrm{C}$. Cell pellets were washed twice with buffer $\mathrm{A}$ $(100 \mathrm{mM}$ Tris $\mathrm{pH} 7.5,150 \mathrm{mM} \mathrm{NaCl})$ and were stored at $-80^{\circ} \mathrm{C}$ until used.

2.3. Pro-Prophenin 2 Purification. Bacterial pellets were thawed and kept on ice, then $1 \mathrm{mg} / \mathrm{mL}$ lysozyme and
$25 \mu \mathrm{g} / \mathrm{mL}$ DNase I were added and incubated 30 minutes at $37^{\circ} \mathrm{C}$ and disrupted with a VirTis sonicator (model VirSonic 60) using 6 pulses of 30 seconds each with 30 -second intervals and a 5-watt output. The soluble phase was recovered by centrifugation at $14,500 \times \mathrm{g}$ for 20 minutes and further clarified by filtering through a $0.2 \mu \mathrm{m}$ syringe filter (Nalgene, Cat. 190-9920). A total of $300 \mu \mathrm{L}$ of anti-Flag M2 affinity gel (Sigma, Cat. A2220) was applied to the supernatant and incubated overnight at $4^{\circ} \mathrm{C}$ with gentle agitation. Anti-Flag M2 affinity gel was recovered and washed 3 times with $2 \mathrm{~mL}$ of TBS (50 mM Tris- $\mathrm{HCl}, 150 \mathrm{mM} \mathrm{NaCl} \mathrm{pH} \mathrm{7.5)/0.02 \%} \mathrm{NaN}_{3}$, and pro-prophenin 2 was eluted with three $6 \mathrm{~mL}$ aliquots of $0.1 \mathrm{M}$ glycine- $\mathrm{HCl}, \mathrm{pH} 3.5$, into Eppendorf tubes containing $20 \mu \mathrm{L}$ of $1 \mathrm{M}$ Tris-HCl, pH 8.0. Anti-Flag M2 affinity gel was reequilibrated to neutral $\mathrm{pH}$ using 30 volumes of TBS. Pro-prophenin 2 was dialyzed using $14 \mathrm{kDa}$ cutoff dialysis tubing (Spectra/Por, Cat. 132678) and concentrated using a Concentrator plus (Eppendorf, Cat. 5305 000.304).

2.4. Hydroxylamine Cleavage of Pro-Prophenin 2. To release the processed peptide, the purified pro-prophenin 2 was incubated $4 \mathrm{~h}$ at $45^{\circ} \mathrm{C}$ in a hydroxylamine reaction mixture (0.22 M Tris, $1.7 \mathrm{M}$ hydroxylamine hydrochloride, $4 \mathrm{M}$ guanidine hydrochloride, and $\mathrm{pH} 9$ ). After incubation, the reaction mixture was incubated in an ice bath for 20 minutes and desalted using an Excellulose GF-5 Desalting Column (Pierce, Cat. 1851850); 10 fractions of $1 \mathrm{~mL}$ each were collected and concentrated using a Concentrator plus (Eppendorf, Cat. $5305000.304)$. Because hydroxylamine cleavage is incomplete, uncleaved propeptide and cathelin were removed by affinity chromatography, using anti-Flag M2 affinity gel as described for pro-prophenin 2 purification.

2.5. Hemolytic Assay. To determine the hemolytic activity of the peptides, fresh human red blood cells were used; peripheral blood was collected from healthy volunteer donors into Vacutainer tubes containing heparin (Cat. 366480) or EDTA (Cat. 366450). Erythrocytes were washed three times with phosphate-buffered saline (PBS, $2.7 \mathrm{mM} \mathrm{KCl}, 10 \mathrm{mM}$ $\mathrm{Na}_{2} \mathrm{HPO}_{4}, 1.8 \mathrm{mM} \mathrm{KH}_{2} \mathrm{PO}_{4}, 150 \mathrm{mM} \mathrm{NaCl}$, and $\mathrm{pH}$ 7.0) and resuspended in $\mathrm{PBS}$ at the originally collected blood volume (erythrocyte concentration of $100 \%$ ). The assay was performed in sterile 96 -well microtiter plates. The final reaction volume was $200 \mu \mathrm{L}$ containing $1 \%$ erythrocytes and different concentrations of pro-prophenin 2, processed peptide, and amidated tritrpticin. Plates were incubated for $1 \mathrm{~h}$ at $37^{\circ} \mathrm{C}$ and centrifuged at $1000 \times \mathrm{g}$ for $5 \mathrm{~min}$. Released hemoglobin was determined by measuring absorbance at $540 \mathrm{~nm}$ in the supernatant. Erythrocyte integrity was calculated according to the hemoglobin released from a $100 \%$ hemolysis control (red cells lysed with $0.1 \%$ Triton X-100) and a negative control (red cells incubated with PBS), using the following formula: $\%$ hemolysis $=\left[\left(\lambda_{540}\right.\right.$ in peptide solution $\left.\lambda_{540} \mathrm{PBS}\right) /\left(\lambda_{540} 0.1 \%\right.$ Triton X-100 $-\lambda_{540}$ PBS $\left.)\right] \times 100$.

2.6. Peptide-Trichomonas Interactions. To determine the effect of the propeptide and processed prophenin 2 on the integrity and growth of $T$. vaginalis, peptide-trichomonas 


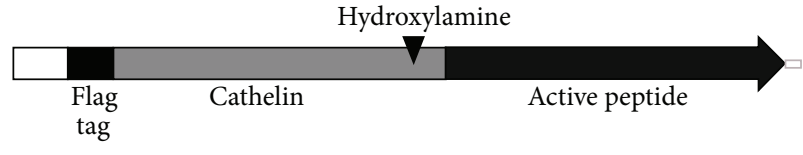

(a)
1

51

101 DQIKDPLDIT CNEGVRRFPW WWPFLRRPRL RRQAFPPPNV PGPRFPPPNV

151 PGPRFPPPNF PGPRFPPPNF PGPRFPPPNF PGPPFPPPIF PGPWFPPPPP

201 FRPPPFGPPR FPGRR

(b)

FIGURE 1: Amino acid sequence of pro-prophenin 2. (a) Graphical representation of the DNA fragment cloned into the pQE-TriSystem. (b) Amino acid sequence. Amino acids derived from the vector (white), Flag tag (black), cathelin (light gray), and processed peptide (dark gray). In (b) the hydroxylamine cleavage site (shaded) and the tritrpticin sequence (underlined) are shown.

assays were performed, as previously described [23]. Briefly, T. vaginalis RFC-1 was grown for $24 \mathrm{~h}$ in screw-cap tubes containing $5 \mathrm{~mL}$ of TYI-S-33. Cell were collected by centrifugation at $1000 \times \mathrm{g}$ for $5 \mathrm{~min}$ and washed with $5 \mathrm{~mL}$ of TYI. The T. vaginalis-peptide interaction took place in 96-well sterile microtiter plates (Corning Inc., USA) containing 40,000 trophozoites and different concentrations of peptide in a final volume of $100 \mu \mathrm{L}$. The medium for the $4 \mathrm{~h}$ interaction assay was TYI supplemented with $25 \mathrm{mM}$ sodium bicarbonate and $100 \mathrm{mM}$ HEPES, pH 7.0. Complete TYI-S-33 culture medium was used for the $24 \mathrm{~h}$ interaction assays. The cultures were incubated at $36.5^{\circ} \mathrm{C}$ in a microaerophilic atmosphere. After incubation, the trophozoite number was calculated using a Neubauer chamber and compared with a control group that did not interact with the peptides. The effect of the different peptide concentrations on $T$. vaginalis was evaluated by ANOVA and a mean comparison using the least significant difference (LSD) test $(\alpha=0.05)$. Using the data obtained, we estimated the $\mathrm{LD}_{50}$ (lethal dosage 50) for the $24 \mathrm{~h}$ interaction, adjusting the model as follows: PERCENT INHIBITION/MORTALITY $=\mathrm{A} * \log ($ DOSAGE $)+\mathrm{B}$, using the $\mathrm{lm}$ function in the $\mathrm{R}$ environment.

\subsection{Stability of Pro-Prophenin 2 to T. vaginalis Proteinases.} The stability of pro-prophenin 2 was determined at 1,2 , and $4 \mathrm{~h}$ of interaction with $T$. vaginalis in TYI supplemented with $25 \mathrm{mM}$ sodium bicarbonate and $100 \mathrm{mM}$ HEPES, $\mathrm{pH}$ 7.0, as described above. A $5 \mu \mathrm{M}$ final concentration of proprophenin 2 was added to 40,000 T. vaginalis trophozoites in a volume of $100 \mu \mathrm{L}$; after incubation at $37^{\circ} \mathrm{C}$, samples were analyzed by Western blot using an anti-Flag antibody. A similar set of samples was incubated in the presence of the cysteine proteinase inhibitor E64.

\section{Results}

3.1. Pro-Prophenin 2 Expression and Purification. To express pro-prophenin 2, a synthetic gene was obtained and cloned into the $\mathrm{pQE}$-TriSystem vector. We verified the correct in-phase insertion of the pro-prophenin 2 open reading frame into the expression vector by restriction analysis and sequencing (LANGEBIO, Irapuato, Mexico). Transformed $E$. coli induced with $1 \mathrm{mM}$ IPTG expressed a protein with the expected molecular weight of the FLAG pro-prophenin 2 fusion protein; however, all of the recombinant protein was found in the pellet. Soluble pro-prophenin 2 was obtained by inducing the cultures with $0.25 \mathrm{mM}$ IPTG, followed by $4 \mathrm{~h}$ incubation at $37^{\circ} \mathrm{C}$ after induction (Figure 2(a), lane 1).

FLAG pro-prophenin 2 was purified by affinity chromatography with an anti-FLAG M2 antibody using a wash buffer containing $300 \mathrm{mM} \mathrm{NaCl}$ and $3 \%$ Tween 20 and exhaustively washing the column to avoid copurification of contaminant proteins (Figure 2(b)). Pro-prophenin 2 yield was $325 \mu \mathrm{g}$ per liter of culture on average.

To obtain the processed portion of prophenin 2, the propeptide was cleaved with hydroxylamine; the cleavage site is located within the cathelin region, 26 amino acid residues upstream the predicted mature peptide (Figure 1(b), shaded residues). Pro-prophenin 2 cleavage with hydroxylamine had an efficiency of approximately $60 \%$ (data not shown). Using an anti-FLAG immunoaffinity column, processed prophenin 2 eluted in the void volume as a single band without binding to the antibody (Figure 2(c)), whereas uncleaved proprophenin 2 as well as the cathelin region was retained.

3.2. Hemolytic Assays. To determine the hemolytic effect of pro-prophenin 2 and the processed peptide, we performed interaction experiments using the peptides pro-prophenin 2 , processed prophenin 2 , and tritrpticin with human red blood cells. Figure 3 shows the integrity of the erythrocytes after $1 \mathrm{~h}$ of interaction with different concentrations of peptides. We observed almost no effect of either the processed peptide or pro-prophenin 2 on human erythrocytes compared with erythrocytes treated with $0.1 \%$ Triton X-100 (100\% hemolysis control). Hemolytic activity of $\mathrm{NH}_{2}$-tritrpticin is shown as control.

3.3. Peptide-Trichomonas Interactions. The effect of prophenin 2 on T. vaginalis was estimated using a $4 \mathrm{~h}$-interaction assay to examine trophozoite integrity, and a $24 \mathrm{~h}$ assay was used to assess parasite growth. After $4 \mathrm{~h}$ incubation with prophenin 2 , refringent trophozoites were decreased by $3 \%$ at $6.25 \mu \mathrm{M}$ to $58 \%$ at $100 \mu \mathrm{M}$ of the processed peptide, showing a dose-dependent effect (Figure 4). Surprisingly, pro-prophenin 2 also had a deleterious effect on $T$. vaginalis integrity, and the effect was dose dependent, similar to the processed peptide (Figure 4).

T. vaginalis grew less at $24 \mathrm{~h}$ in the presence of proprophenin 2 or processed peptide compared with the culture in the absence of the peptides. Growth was reduced by 


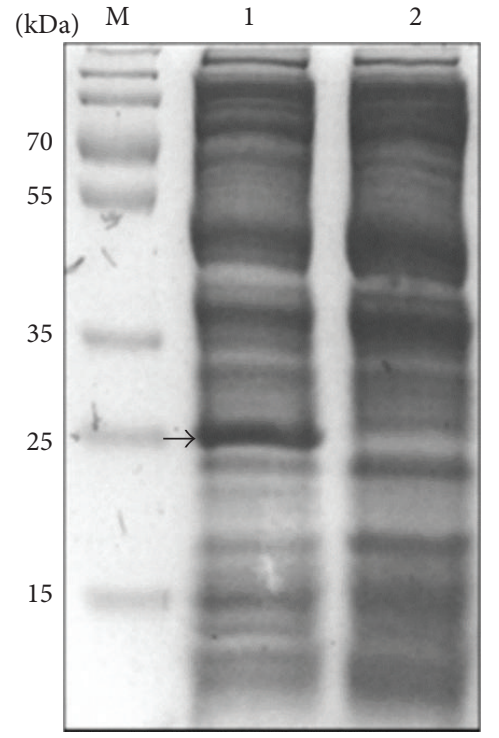

(a)

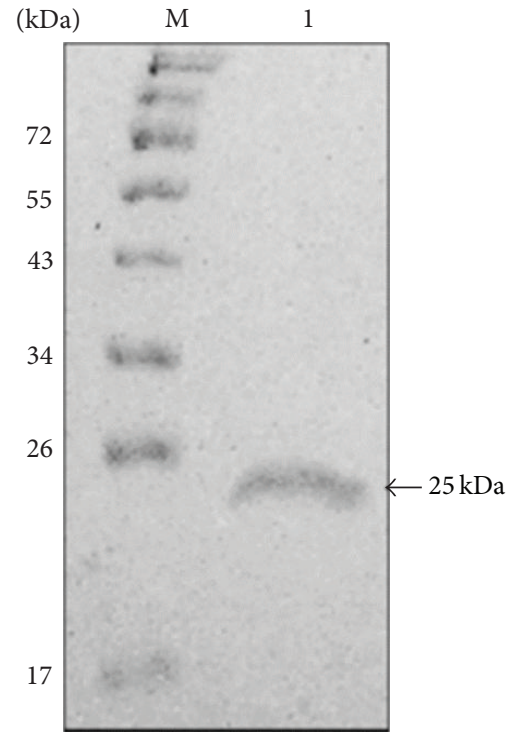

(b)

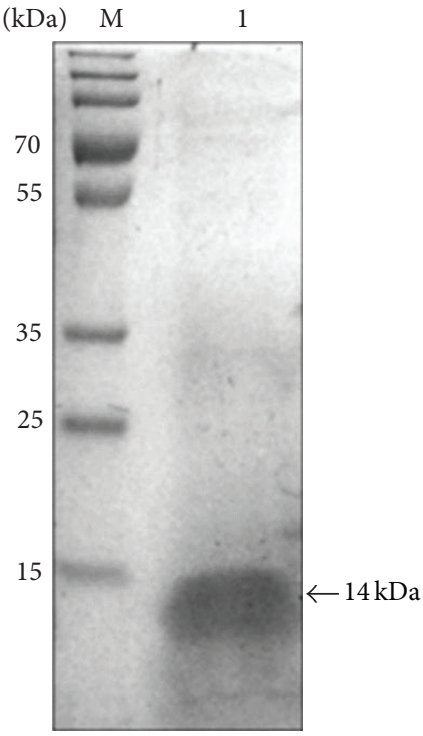

(c)

FIGURE 2: Electrophoretic analysis of pro-prophenin 2 expression, purification, and cleavage with hydroxylamine. Twelve percent polyacrylamide gels (20:1 acrylamide : bis-acrylamide) were used and proteins were stained with Coomassie blue. (a) Pro-prophenin 2 expression: lane 1, crude extract from E. coli BL21 STAR induced $4 \mathrm{~h}$ with $0.25 \mathrm{mM}$ IPTG; lane 2, crude extract from uninduced E. coli BL21 STAR, otherwise grown as induced. (b) Pro-prophenin 2 purified by affinity chromatography (lane 1). (c) Processed prophenin 2 after hydroxylamine cleavage and purification (lane 1). M: molecular weight markers.

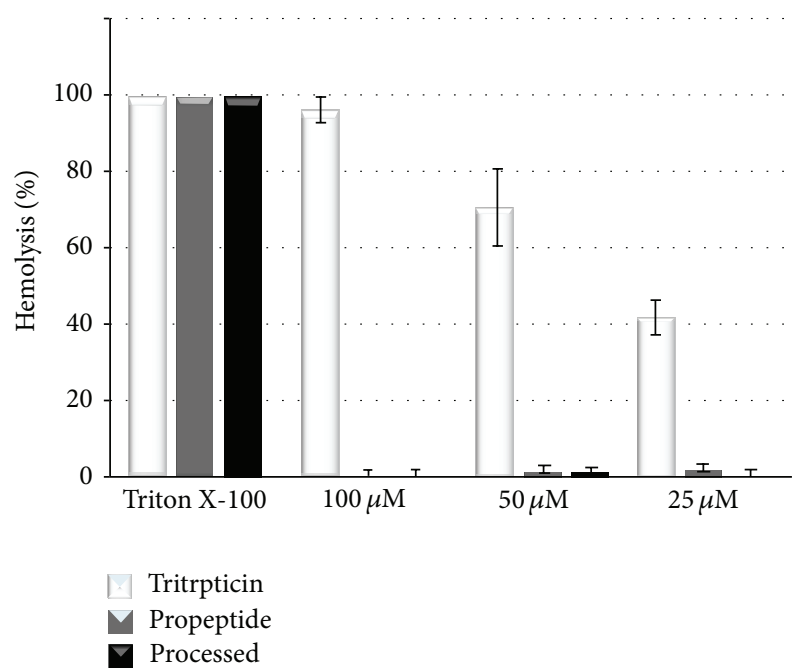

FIgURE 3: Hemolytic activity of prophenin 2. The percentage of hemolysis was calculated from the absorbance at $540 \mathrm{~nm}$ of the supernatants after $1 \mathrm{~h}$ of interaction of red blood cells with proprophenin 2, processed peptide, and $\mathrm{NH}_{2}$-tritrpticin. Hemolysis of $100 \%$ was obtained by the treatment of erythrocytes with $0.1 \%$ Triton $\mathrm{X}-100$.

$12 \%$ at $6.25 \mu \mathrm{M}$ and by $60 \%$ at $100 \mu \mathrm{M}$ of the processed peptide (Figure 5(a)). The results demonstrated high reproducibility because the standard error was low (11.24). Comparing the means of every treatment, we observed a dosedependent effect on the integrity and growth of $T$. vaginalis and found that the $\mathrm{LD}_{50}$ is approximately $50 \mu \mathrm{M}$ of the processed peptide. Based on the linear regression analysis of

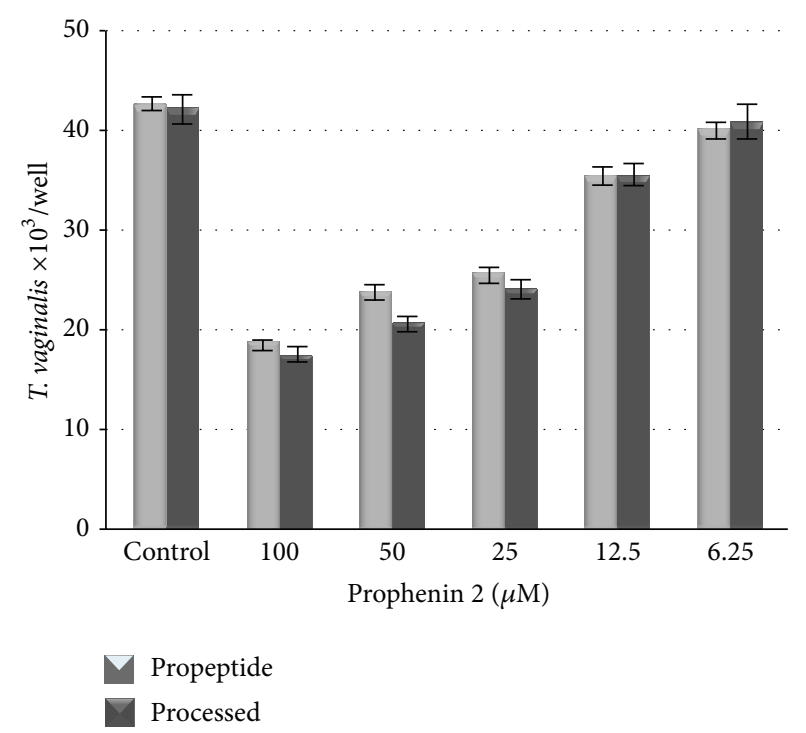

FIGURE 4: Effect of prophenin 2 on T. vaginalis integrity. Trophozoites were inoculated in TYI-HEPES-sodium bicarbonate at 40,000 cells/well; serial dilutions of prophenin 2 were added and incubated at $36.5^{\circ} \mathrm{C}$ for $4 \mathrm{~h}$. After incubation, each well was sampled and trophozoites were counted. The size of the sample for every treatment was $n=44-48$, and the standard errors observed were 1.18 or less.

the equation described in Section 2, we determined that the $\mathrm{LD}_{50}$ for the processed peptide was $47.66 \mu \mathrm{M}$ (Figure 5(b)). The significance level of the regression was $P=2.2 e-16$, indicating an effect on the growth of $T$. vaginalis. 


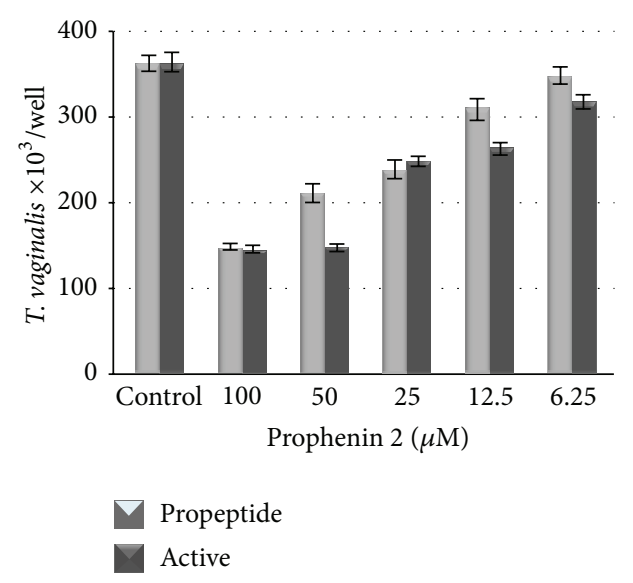

(a)

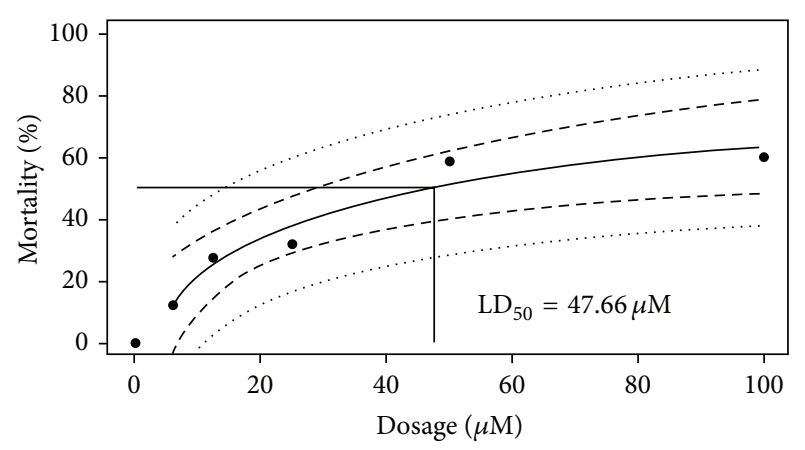

(b)

FIGURE 5: Effect of prophenin 2 on T. vaginalis growth. (a) Trophozoites were inoculated in TYI-S-33 at 40,000 cells/well; serial dilutions of pro-prophenin 2 were added and incubated at $36.5^{\circ} \mathrm{C}$ for $24 \mathrm{~h}$. After incubation, each well was sampled, and trophozoites were counted. The size of the sample for every treatment was $n=44-48$, and the standard errors observed were 1.18 or less. (b) Estimated $\mathrm{LD}_{50}$ for prophenin 2 . The results from $24 \mathrm{~h}$ interaction assays were used to construct a linear regression model, and the $\mathrm{LD}_{50}$ was estimated to be $47.66 \mu \mathrm{M}$.

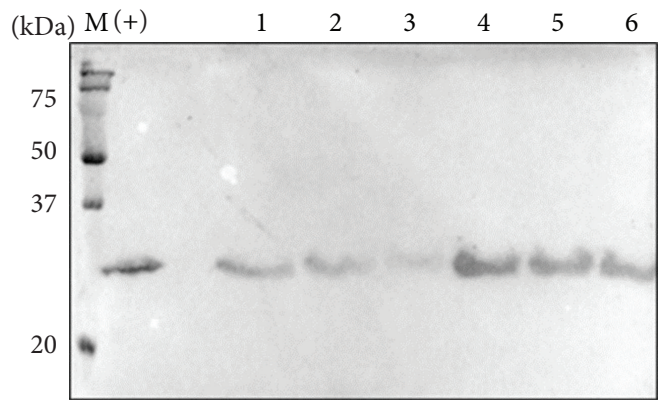

(a)

\begin{tabular}{|cccccccc|}
\hline Sample & $(+)$ & 1 & 2 & 3 & 4 & 5 & 6 \\
\hline Signal intensity & 5.74 & 2.66 & 1.21 & 0.92 & 7.71 & 5.67 & 3.79 \\
Relative intensity & 1 & 0.46 & 0.21 & 0.16 & 1.34 & 0.98 & 0.66 \\
\hline
\end{tabular}

(b)

FIGURE 6: Stability of pro-prophenin 2 after interaction with T. vaginalis. (a) After parasite-peptide interaction at several incubation times, contents of wells (cells + supernatant) were analyzed by Western blot using anti-FLAG M2 antibodies and signal developed with luminol. Lane M: molecular weight markers; lane (+): $5 \mu \mathrm{M}$ pro-prophenin 2 as a positive control. Lanes 1 to 3: T. vaginalis with $5 \mu \mathrm{M}$ pro-prophenin 2 incubated 1,2, and $4 \mathrm{~h}$, respectively. Lanes 4 to 6: same as lanes 1 to 3 but in the presence of $10 \mu \mathrm{M}$ E64. (b) Signal intensity analysis is done with Image Lab software (BioRad).

3.4. Stability of Pro-Prophenin 2 to T. vaginalis Proteinases. Previous work in our group demonstrated that human cathelicidin LL-37 is very sensitive to proteases from E. histolytica, being degraded in just one hour [28]. We decided to test the stability of pro-prophenin 2 by Western blot of the propeptide after 1,2 , and $4 \mathrm{~h}$ of interaction with $T$. vaginalis, using the anti-FLAG M2 antibody. We detected the presence of proprophenin 2 in all lanes (Figure 6), even in samples that were not treated with the cysteine proteinase inhibitor E64; although after $4 \mathrm{~h}$ interaction, without E-64, the signal was very weak (lane 3 ).

\section{Discussion}

This study demonstrated that recombinant prophenin 2, both the propeptide and the processed peptide, diminished the integrity and growth of T. vaginalis. Prophenin 2 belongs to the porcine cathelicidin family, which are host defense peptides sharing a highly conserved N-terminal cathelin region homologous to the cathepsin L inhibitor [29]. Pigs possess the largest number of cathelicidins described for a single species, with 11 members [10, 30]. Originally, the sequence of prophenin was described by Pungercar et al. in 1993 from a cDNA clone [31]. Later, the protein prophenin1 was purified and characterized as a 79 aa fragment from porcine leukocytes. It is rich in proline and phenylalanine and contains 5 nearly perfect tandem repeats of a prolinerich decamer, FPPPNFPGPR [32]. Additionally, Zhao et al. [26] reported a closely related sequence named prophenin 2. To date, much of the work performed with prophenin has focused on a small derivative named tritrpticin, which is 13 amino acid residues long and possesses 3 consecutive tryptophan residues. Most studies have used bacteria $[33,34]$, and only our group has reported the effect of tritrpticin on a protozoa [23]. In this work we expressed the recombinant pro-prophenin 2; although the yield was low (about 
$300 \mu \mathrm{g} / \mathrm{L}$ ), this can likely be circumvented using vectors that fuse pro-prophenin 2 to thioredoxin or glutathione $\mathrm{S}$ transferase; we are currently pursuing this line of research.

The use of vital staining to determine viability of $T$. vaginalis in studies involving interaction with antimicrobial peptides is not a suitable methodology, since these molecules alter the cell membrane making it more permeable to the colorant [4]. In a previous report, we demonstrate that after treatment with tritrpticin, the number of refringent $T$. vaginalis trophozoites correlates with their ability to growth [23]. Additionally we observed that tritrpticin at $105 \mu \mathrm{M}$ reduced $T$. vaginalis viability by approximately $72 \%$ after $3 \mathrm{~h}$ of interaction and that it reduced growth by $58 \%$ after $24 \mathrm{~h}$ of interaction [23]. In this study, we reported similar results, with a reduction of $58 \%$ in $T$. vaginalis integrity at $100 \mu \mathrm{M}$ of processed prophenin 2 in $4 \mathrm{~h}$ interaction assays and a decrease of $60 \%$ in T. vaginalis growth using $100 \mu \mathrm{M}$ of processed peptide in $24 \mathrm{~h}$ interaction assays.

A major concern regarding the possible therapeutic use of C-terminus amidated tritrpticin is the hemolytic activity, as it demonstrates $\sim 50 \%$ hemolysis at $30 \mu \mathrm{M}$ [35]. Our work demonstrated that prophenin 2 presents very low hemolytic activity against human red blood cells. This hemolytic activity has to be determined on an individual case basis because it depends not only on the surface selectivity of the target membrane based on the lipid composition [36], but also on the composition of the peptide itself [37]. We demonstrated that prophenin 2 presented good trichomonacidal activity and very low hemolytic activity, which makes this molecule an attractive candidate for studying its possible use as a synergistic or alternative therapy.

In nature, it is accepted that prophenin 2 is processed by neutrophil elastase [38, 39]; the proteolytic cleavage site is predicted between Gly114 and Val115 to release a 101 aa mature peptide [26]. In this study we used as the processed prophenin 2 , the portion obtained by cleavage of the recombinant propeptide at a naturally occurring hydroxylamine site (cleavage site Asp88-Gly89), which contained 26 extra amino acids at the $\mathrm{N}$-terminus of the predicted mature peptide. We do not know if these extra amino acids affect the activity of the peptide because the antimicrobial activity of the mature peptide of prophenin 2 is unknown. However, the 79-80 and 17-18 aa prophenin peptides isolated from porcine leukocytes $[32,40,41]$ have antibacterial activity. The predicted site for processing the propeptide includes 18 amino acids more than the 79 aa peptide isolated from leukocytes [26]; these fragments and the 17-18 aa long peptide may be produced by additional processing of the mature peptide.

In porcine leukocytes, prophenins are amidated at the $\mathrm{C}$ terminus $[40,41]$, and this extra positive charge may contribute to the binding of negatively charged targets; therefore, it is expected that the amidated version of the peptide tested in this study will be active at lower concentrations against $T$. vaginalis.

Interestingly, our results demonstrate similar anti-T. vaginalis activity of recombinant pro-prophenin as the processed peptide, which is in accordance with the observation that the human pro-cathelicidin HCap18 has similar antimicrobial activity than the C-terminal LL-37 active peptide [42].
T. vaginalis secretes cysteine proteinases as virulence factors, and these enzymes may negatively affect the integrity of most antimicrobial peptides. It is proposed that the prolinerich sequences of some mature cathelicidins are naturally resistant to serine proteases because these types of sequences are very poor substrates for proteolysis $[10,24]$. In this study, we demonstrated that pro-prophenin 2 displays an acceptable stability after $1 \mathrm{~h}$ of interaction with $T$. vaginalis because protein degradation is not as evident as in our previous work with peptides derived from human cathelicidin LL-37 [28]. We did not test the stability of processed prophenin 2 after interaction with $T$. vaginalis because no antibody targeting the mature peptide was available.

\section{Conclusions}

We conclude that $T$. vaginalis integrity and growth were significantly diminished in the presence of prophenin 2 . Although $T$. vaginalis secretes very active cysteine proteinases, pro-prophenin 2 partially overcomes this limitation, which is inherent to antimicrobial peptides, making prophenin 2 an interestingly candidate for alternative $T$. vaginalis treatment.

\section{Conflict of Interests}

The authors declare that there is no conflict of interests regarding the publication of this paper.

\section{Acknowledgments}

This study was supported by grants from Consejo Nacional de Ciencia y Tecnologia, Mexico (Grant no. CB-2012-01 182671) and Universidad de Guanajuato (Grant no. 2013-310).

\section{References}

[1] K. A. Brogden, M. Ackermann, P. B. McCray Jr., and B. F. Tack, "Antimicrobial peptides in animals and their role in host defences," International Journal of Antimicrobial Agents, vol. 22, no. 5, pp. 465-478, 2003.

[2] G. Maróti Gergely, A. Kereszt, É. Kondorosi, and P. Mergaert, "Natural roles of antimicrobial peptides in microbes, plants and animals," Research in Microbiology, vol. 162, no. 4, pp. 363-374, 2011.

[3] A. A. Bahar and D. Ren, "Antimicrobial peptides," Pharmaceuticals, vol. 6, no. 12, pp. 1543-1575, 2013.

[4] G. K. Mutwiri, W. G. Henk, F. M. Enright, and L. B. Corbeil, "Effect of the antimicrobial peptide, D-hecate, on Trichomonads," Journal of Parasitology, vol. 86, no. 6, pp. 1355-1359, 2000.

[5] J. Vizioli and M. Salzet, "Antimicrobial peptides versus parasitic infections?" Trends in Parasitology, vol. 18, no. 11, pp. 475-476, 2002.

[6] A. J. Mason, W. Moussaoui, T. Abdelrahman et al., "Structural determinants of antimicrobial and antiplasmodial activity and selectivity in histidine-rich amphipathic cationic peptides," The Journal of Biological Chemistry, vol. 284, no. 1, pp. 119-133, 2009.

[7] C.-Y. Pan, J.-Y. Chen, T.-L. Lin, and C.-H. Lin, "In vitro activities of three synthetic peptides derived from epinecidin-1 and an 
anti-lipopolysaccharide factor against Propionibacterium acnes, Candida albicans, and Trichomonas vaginalis," Peptides, vol. 30, no. 6, pp. 1058-1068, 2009.

[8] L. Rivas, J. R. Luque-Ortega, and D. Andreu, "Amphibian antimicrobial peptides and Protozoa: lessons from parasites," Biochimica et Biophysica Acta, vol. 1788, no. 8, pp. 1570-1581, 2009.

[9] B. Rivas-Santiago, C. J. Serrano, and J. A. Enciso-Moreno, "Susceptibility to infectious diseases based on antimicrobial peptide production," Infection and Immunity, vol. 77, no. 11, pp. 4690-4695, 2009.

[10] Y. Sang and F. Blecha, "Porcine host defense peptides: expanding repertoire and functions," Developmental \& Comparative Immunology, vol. 33, no. 3, pp. 334-343, 2009.

[11] M. F. Cotch, J. G. Pastorek II, R. P. Nugent et al., “Trichomonas vaginalis associated with low birth weight and preterm delivery. The Vaginal Infections and Prematurity Study Group," Sexually Transmitted Diseases, vol. 24, no. 6, pp. 353-360, 1997.

[12] M. Laga, A. Manoka, M. Kivuvu et al., "Non-ulcerative sexually transmitted diseases as risk factors for HIV-1 transmission in women: Results from a cohort study," AIDS, vol. 7, no. 1, pp. 95102, 1993.

[13] G. G. G. Donders, C. E. Depuydt, J.-P. Bogers, and A. J. Vereecken, "Association of Trichomonas vaginalis and cytological abnormalities of the cervix in low risk women," PLoS ONE, vol. 8, no. 12, Article ID e86266, 2013.

[14] P. Kissinger and A. Adamski, "Trichomoniasis and HIV interactions: a review," Sexually Transmitted Infections, vol. 89, no. 6, pp. 426-433, 2013.

[15] S. L. Cudmore, K. L. Delgaty, S. F. Hayward-McClelland, D. P. Petrin, and G. E. Garber, "Treatment of infections caused by metronidazole-resistant Trichomonas vaginalis," Clinical Microbiology Reviews, vol. 17, no. 4, pp. 783-793, 2004.

[16] D. H. H. Robertson, R. Heyworth, C. Harrison, and W. H. R. Lumsden, "Treatment failure in Trichomonas vaginalis infections in females. I. Concentrations of metronidazole in plasma and vaginal content during normal and high dosage," Journal of Antimicrobial Chemotherapy, vol. 21, no. 3, pp. 373-378, 1988.

[17] R. L. Dunne, L. A. Dunn, P. Upcroft, P. J. O’Donoghue, and J. A. Upcroft, "Drug resistance in the sexually transmitted protozoan Trichomonas vaginalis," Cell Research, vol. 13, no. 4, pp. 239249, 2003.

[18] J. R. Schwebke and F. J. Barrientes, "Prevalence of Trichomonas vaginalis isolates with resistance to metronidazole and tinidazole," Antimicrobial Agents and Chemotherapy, vol. 50, no. 12, pp. 4209-4210, 2006.

[19] J. D. Sobel, V. Nagappan, and P. Nyirjesy, "Metronidazoleresistant vaginal trichomoniasis-an emerging problem," The New England Journal of Medicine, vol. 341, no. 4, pp. 292-293, 1999.

[20] H. Hernández, I. Sariego, G. Garber, R. Delgado, O. López, and J. Sarracent, "Monoclonal antibodies against a $62 \mathrm{kDa}$ proteinase of Trichomonas vaginalis decrease parasite cytoadherence to epithelial cells and confer protection in mice," Parasite Immunology, vol. 26, no. 3, pp. 119-125, 2004.

[21] R. Hernández-Gutiérrez, L. Avila-González, J. Ortega-López, F. Cruz-Talonia, G. Gómez-Gutierrez, and R. Arroyo, "Trichomonas vaginalis: characterization of a $39-\mathrm{kDa}$ cysteine proteinase found in patient vaginal secretions," Experimental Parasitology, vol. 107, no. 3-4, pp. 125-135, 2004.

[22] A. F. Garcia and J. F. Alderete, "Characterization of the Trichomonas vaginalis surface-associated AP65 and binding domain interacting with trichomonads and host cells," $B M C$ Microbiology, vol. 7, article 116, 2007.

[23] V. V. Infante, A. D. Miranda-Olvera, L. M. de Leon-Rodriguez, F. Anaya-Velazquez, M. C. Rodriguez, and E. E. Avila, "Effect of the antimicrobial peptide tritrpticin on the in vitro viability and growth of trichomonas vaginalis," Current Microbiology, vol. 62, no. 1, pp. 301-306, 2011.

[24] A. E. Shinnar, K. L. Butler, and H. J. Park, "Cathelicidin family of antimicrobial peptides: proteolytic processing and protease resistance," Bioorganic Chemistry, vol. 31, no. 6, pp. 425-436, 2003.

[25] L. S. Diamond, D. R. Harlow, and C. C. Cunnick, "A new medium for the axenic cultivation of Entamoeba histolytica and other Entamoeba," Transactions of the Royal Society of Tropical Medicine and Hygiene, vol. 72, no. 4, pp. 431-432, 1978.

[26] C. Zhao, T. Ganz, and R. I. Lehrer, "Structures of genes for two cathelin-associated antimicrobial peptides: prophenin-2 and PR-39," FEBS Letters, vol. 376, no. 3, pp. 130-134, 1995.

[27] T. P. Hopp, K. S. Prickett, V. L. Price et al., "A short polypeptide marker sequence useful for recombinant protein identification and purification," Nature Biotechnology, vol. 6, no. 10, pp. 12041210, 1988.

[28] R. Rico-Mata, L. M. De Leon-Rodriguez, and E. E. Avila, "Effect of antimicrobial peptides derived from human cathelicidin LL-37 on Entamoeba histolytica trophozoites," Experimental Parasitology, vol. 133, no. 3, pp. 300-306, 2013.

[29] A. Ritonja, M. Kopitar, R. Jerala, and V. Turk, "Primary structure of a new cysteine proteinase inhibitor from pig leucocytes," FEBS Letters, vol. 255, no. 2, pp. 211-214, 1989.

[30] G. Zhang, C. R. Ross, and F. Blecha, "Porcine antimicrobial peptides: new prospects for ancient molecules of host defense," Veterinary Research, vol. 31, no. 3, pp. 277-296, 2000.

[31] J. Pungercar, B. Strukelj, G. Kopitar et al., "Molecular cloning of a putative homolog of proline/arginine-rich antibacterial peptides from porcine bone marrow," FEBS Letters, vol. 336, no. 2, pp. 284-288, 1993.

[32] S. S. Harwig, V. N. Kokryakov, K. M. Swiderek, G. M. Aleshina, C. Zhao, and R. I. Lehrer, "Prophenin-1, an exceptionally proline-rich antimicrobial peptide from porcine leukocytes," FEBS Letters, vol. 362, pp. 65-69, 1995.

[33] C. Lawyer, S. Pai, M. Watabe et al., "Antimicrobial activity of a 13 ammo acid tryptophan-rich peptide derived from a putative porcine precursor protein of a novel family of antibacterial peptides," The FEBS Letters, vol. 390, no. 1, pp. 95-98, 1996.

[34] O. Cirioni, A. Giacometti, C. Silvestri et al., "In vitro activities of tritrpticin alone and in combination with other antimicrobial agents against Pseudomonas aeruginosa," Antimicrobial Agents and Chemotherapy, vol. 50, no. 11, pp. 3923-3925, 2006.

[35] L. T. Nguyen, L. de Boer, S. A. J. Zaat, and H. J. Vogel, "Investigating the cationic side chains of the antimicrobial peptide tritrpticin: hydrogen bonding properties govern its membrane-disruptive activities," Biochimica et Biophysica Acta: Biomembranes, vol. 1808, no. 9, pp. 2297-2303, 2011.

[36] Y. Ishitsuka, D. S. Pham, A. J. Waring, R. I. Lehrer, and K. Y. C. Lee, "Insertion selectivity of antimicrobial peptide protegrin-1 into lipid monolayers: effect of head group electrostatics and tail group packing," Biochimica et Biophysica Acta, vol. 1758, no. 9, pp. 1450-1460, 2006.

[37] S.-T. Yang, S. Yub Shin, Y.-C. Kim, Y. Kim, K.-S. Hahm, and J. I. Kim, "Conformation-dependent antibiotic activity of tritrpticin, a cathelicidin-derived antimicrobial peptide," Biochemical 
and Biophysical Research Communications, vol. 296, no. 5, pp. 1044-1050, 2002.

[38] A. M. Cole, J. Shi, A. Ceccarelli, Y.-H. Kim, A. Park, and T. Ganz, "Inhibition of neutrophil elastase prevents cathelicidin activation and impairs clearance of bacteria from wounds," Blood, vol. 97, no. 1, pp. 297-304, 2001.

[39] J. Shi and T. Ganz, "The role of protegrins and other elastaseactivated polypeptides in the bactericidal properties of porcine inflammatory fluids," Infection and Immunity, vol. 66, no. 8, pp. 3611-3617, 1998.

[40] Y. Wang, W. J. Griffiths, T. Curstedt, and J. Johansson, "Porcine pulmonary surfactant preparations contain the antibacterial peptide prophenin and a C-terminal 18-residue fragment thereof," The FEBS Letters, vol. 460, no. 2, pp. 257-262, 1999.

[41] Y. Wang, J. Johansson, and W. J. Griffiths, "Characterisation of variant forms of prophenin: mechanistic aspects of the fragmentation of proline-rich peptides," Rapid Communications in Mass Spectrometry, vol. 14, no. 23, pp. 2182-2202, 2000.

[42] M. Pazgier, B. Ericksen, M. Ling et al., "Structural and functional analysis of the pro-domain of human cathelicidin, LL-37," Biochemistry, vol. 52, no. 9, pp. 1547-1558, 2013. 

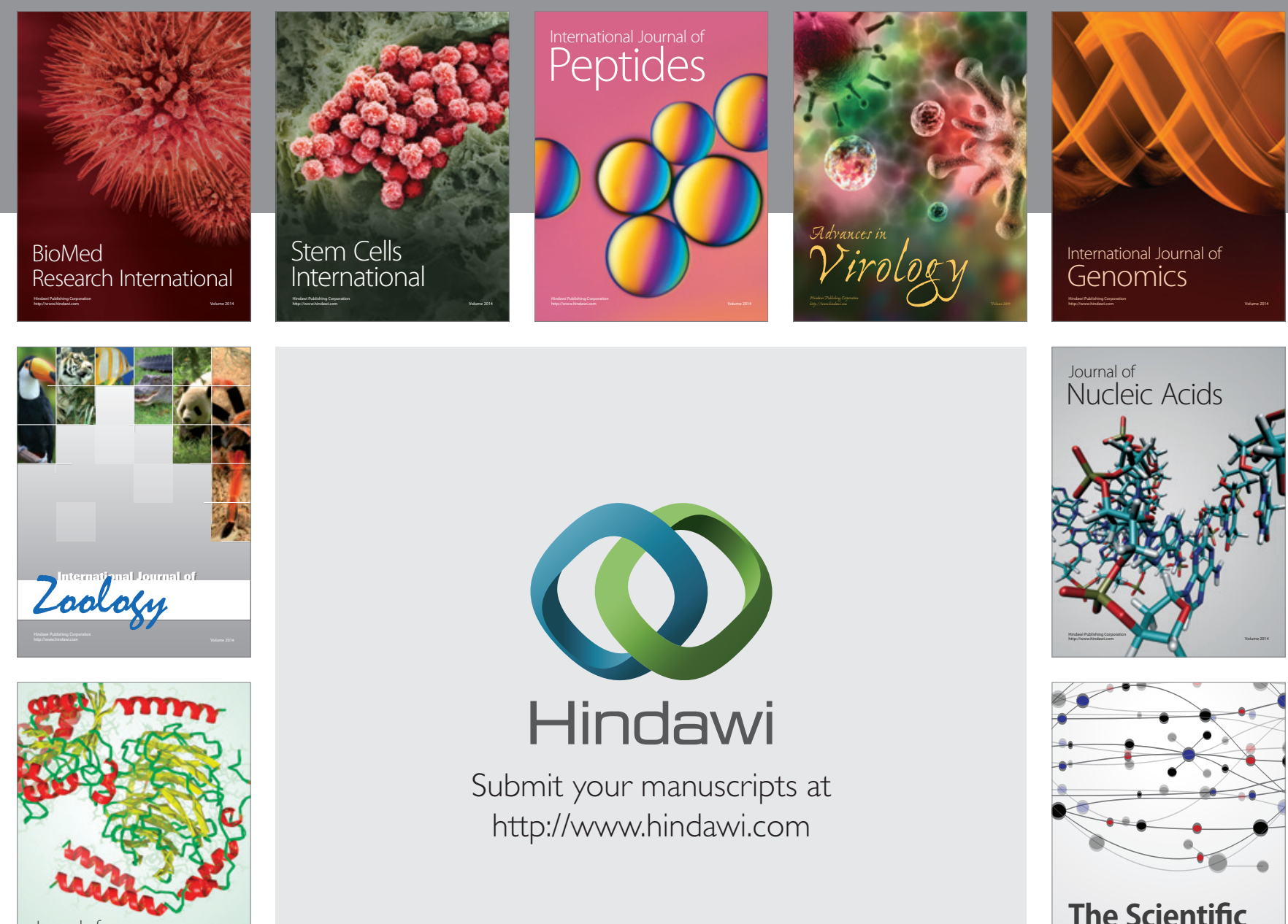

Submit your manuscripts at

http://www.hindawi.com

Journal of
Signal Transduction
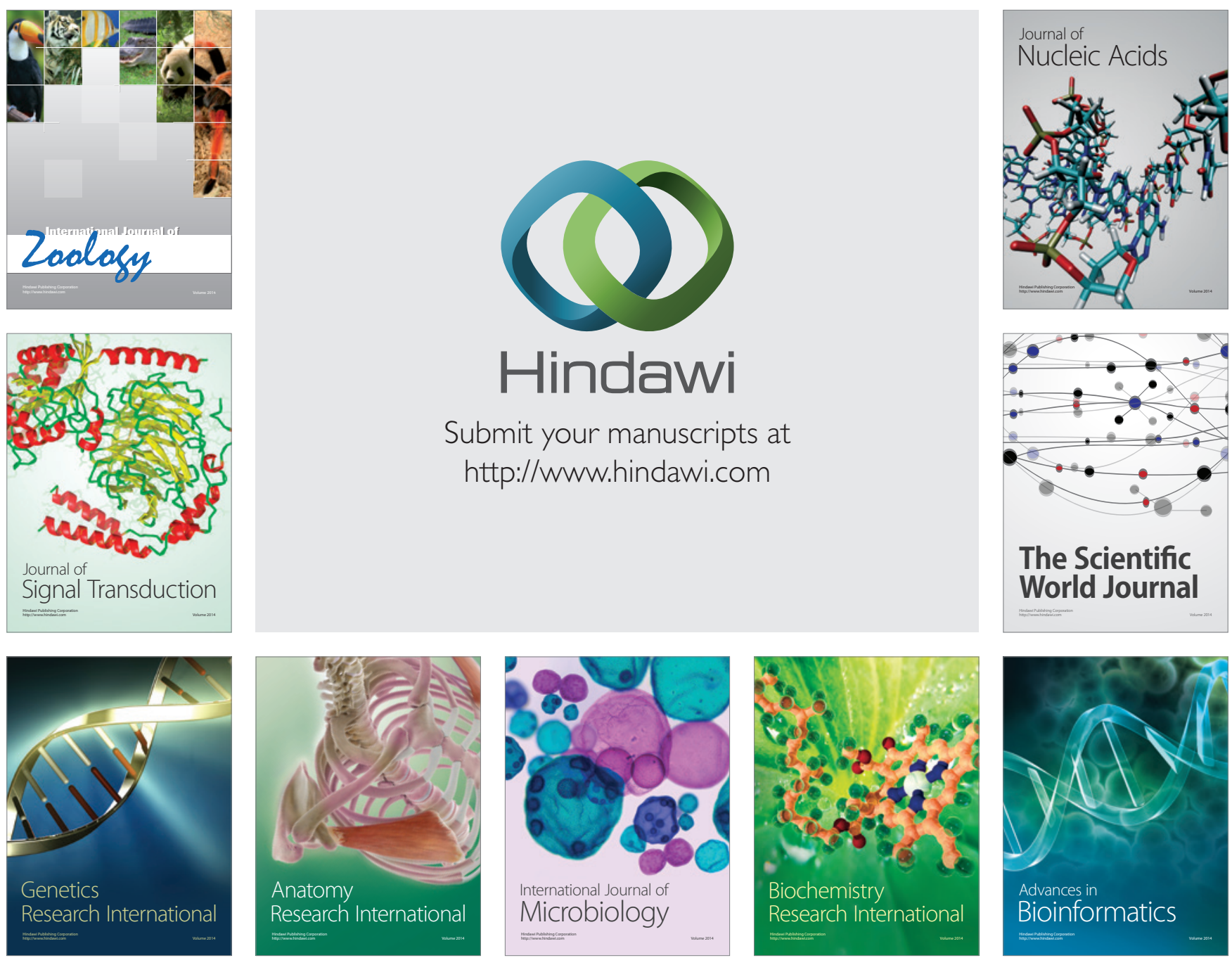

The Scientific World Journal
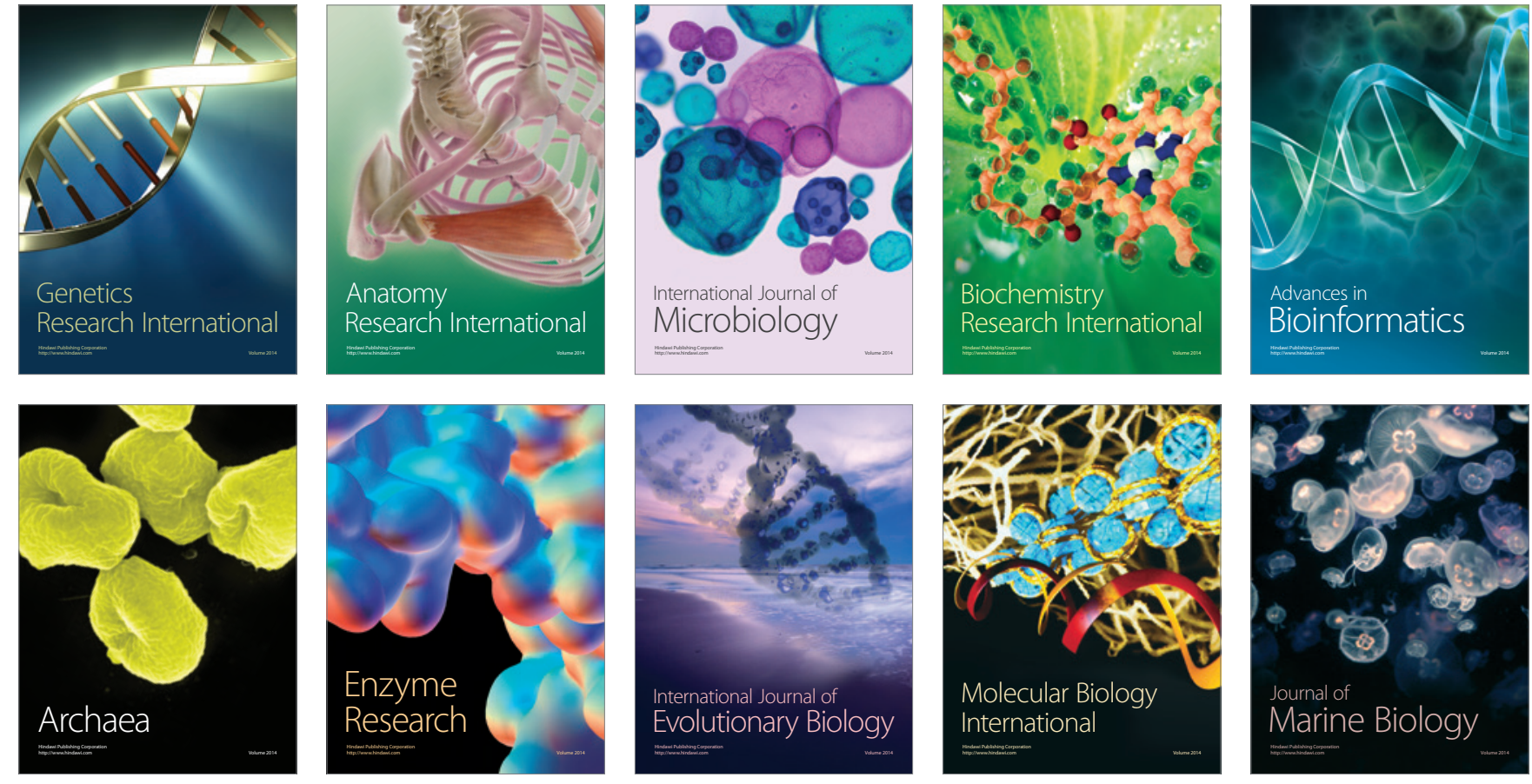